Original Research Article

\title{
Study of drug utilization pattern in emergency medicine ward at a tertiary care teaching hospital
}

\author{
Mamatha V.*, Parashivamurthy B. M., Suneetha D. K.
}

Department of Pharmacology, Mysore Medical College and Research Institute, Mysore, Karnataka, India

Received: 20 January 2017 Accepted: 25 February 2017

\section{*Correspondence to:}

Dr. Mamatha V.,

Email: v.mamta120@gmail.com

Copyright: (c) the author(s), publisher and licensee Medip Academy. This is an openaccess article distributed under the terms of the Creative Commons Attribution NonCommercial License, which permits unrestricted noncommercial use, distribution, and reproduction in any medium, provided the original work is properly cited.

\begin{abstract}
Background: The emergency department represents an important platform for conducting drug utilization studies as patients present with a wide spectrum of diseases in acute form. An irrational prescription adversely affects the prognosis and recovery of patients. Hence, the objective of our study was to evaluate the drug utilization pattern and to determine the rationality of prescription using WHO prescribing indicators in emergency medicine ward.

Methods: After obtaining Institutional Ethical Committee approval, a prospective observational study was conducted over 2 months. The case records of 150 patients admitted to the emergency medicine ward, with a hospital stay of more than $24 \mathrm{hrs}$ were reviewed to analyze the prescription pattern during the initial $48 \mathrm{hrs}$ of admission. Case records of patients irrespective of age, sex and diagnosis were included in the study. Descriptive statistics were used to analyze the results (SPSS version 20).

Results: A total of 1014 drugs were prescribed from 150 case records with a mean age of $47 \pm 18$ years. An average of 6.76 drugs was prescribed per prescription; percentage of encounters with at least an antimicrobial was 115 $(76.66 \%)$. Injections were prescribed in all patients $(100 \%)$ and only 416 $(41.02 \%)$ drugs were prescribed by generic name and $657(64.79 \%)$ drugs abided to the WHO essential drug list. Majority of patients received antiulcerogenic drugs followed by antimicrobials.

Conclusions: There was a tendency of polypharmacy with overuse of PPIs and antimicrobials. There is need to rationalize the drug therapy in terms of increasing prescription of drugs from essential drug list by generic name.
\end{abstract}

Keywords: Drug utilization, Polypharmacy, WHO prescribing indicators

\section{INTRODUCTION}

The World Health Organization (WHO) defines the Drug utilization research as the marketing, distribution, prescription, and use of drugs in a society, with special emphasis on the resulting medical, social and economic consequences. ${ }^{1}$ Drug utilization study is an essential part of pharmacoepidemiology that analyses the prescribing patterns, justifies the rational use of drugs and its impact on healthcare system. ${ }^{1}$ These studies provide background for determining the rationality of drug use as well as provides evidence based guidance for making policy decisions at various levels of healthcare. ${ }^{2}$

Rational prescription utilizes updated knowledge and adherence to prescribing policies. Irrational prescription leads to unproductive and unsafe treatment, that manifests in either exacerbation or prolongation of illness, distress and harm to the patient or higher costs. ${ }^{3}$ Appropriate medication use is of both clinical and economic significance to any health system and should be given adequate attention. ${ }^{4}$

There are very few pharmaco-epidemiological studies in developing countries about prescribing patterns. ${ }^{4}$ The emergency department (ED) represents an important platform for conducting drug utilization studies as patients present with a wide spectrum of diseases in acute form \& drug usage is quite extensive. ${ }^{2}$ Physicians often face challenges in selecting, initiating, and individualizing appropriate drug therapy for patients in the emergency department. Currently, there is limited 
data on the drug utilization pattern at the ED. ${ }^{2}$ Hence, this study has the potential of determining the rationality of drug therapy. This study was conducted to evaluate the drug utilization pattern and to determine the rationality of prescription using WHO prescribing indicators in inpatients of emergency medicine department of a tertiary care hospital to identify the priority areas that need to be targeted for further improvement in patient care.

\section{METHODS}

\section{Setting and study design}

A prospective observational study was conducted over a period of 2 months during 2015 in emergency medicine ward of a tertiary care hospital at Mysore after obtaining Institutional Ethical Committee clearance. Our Institute is a tertiary care teaching hospital which caters to needs of a large patient pool from both urban and rural areas of this region. Medical emergency unit has 30 beds and has a turnover of about 1000 patients per month. All patients presenting with any emergency medical need are attended by Internal medicine specialists in the emergency department for initial management.

\section{Study population}

Prescriptions of inpatients of both sex, aged 18 years and more, with two or more drugs, who stayed for more than 24 hours were included in the study. The complete prescription was recorded in predesigned case record form for first 48 hours of admission. Case records of subjects who die during the stay were excluded from the study.

Estimated sample size was 144 case records based on proportion of subjects staying more than 24 hours to total admissions in emergency ward. A total of 150 prescriptions were analyzed. Demographic data like age and sex were noted. The clinical data comprising diagnosis, name of the drugs and their route of administration were recorded. Confidentiality of study subjects was maintained. The data thus obtained was analyzed to arrive at the WHO core prescribing indicators mentioned below.

The World Health Organization (WHO) has compiled a set of core drug use indicators that are useful for studying patterns of drug prescribing in health care facilities. ${ }^{5,6}$

WHO core prescribing indicators:

- Average number of drugs per prescription

- Percentage of prescription with antibiotics.

- Percentage of prescription with injection

- Percentage of drugs prescribed by generic names

- Percentage of drugs prescribed from the essential drug list.
The 19th WHO model list of essential medicine (April 2015) was used in our study. ${ }^{7}$

\section{Statistical analysis}

Data were entered into Microsoft Excel and analysed using the Statistical Package for Social Sciences (SPSS) for Windows software (version 20.0). Descriptive statistics such as mean for continuous variables and frequency and percentage for categorical variables were determined.

\section{RESULTS}

\section{Demographic profile}

A total of 150 case records were reviewed. Among the case records, 98 were males and 52 were females with ratio of 1.88:1. The mean age group of patients admitted was $47.5 \pm 18$ years ranging from 18-80 years. Majority of patients were adults between $20-59$ years $(n=97,64.7 \%)$.

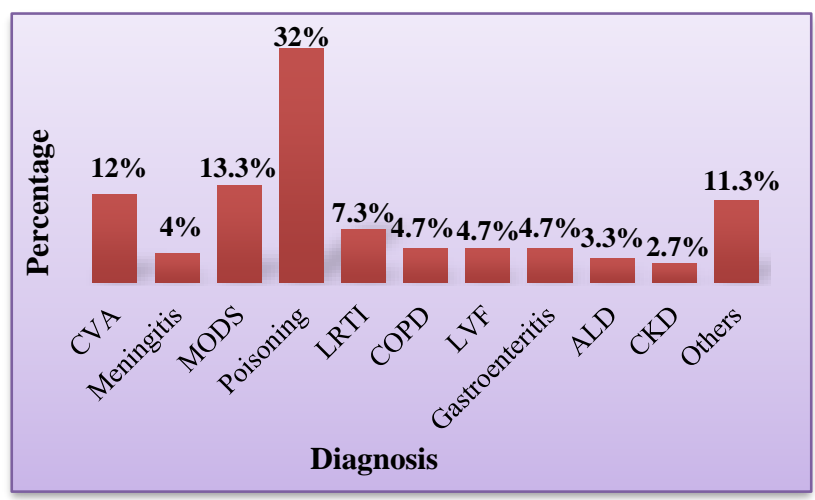

CVA: Cerebrovascular accident, MODS: Multi organ dysfunction syndrome, LRTI: Lower respiratory tract infection, COPD: Chronic obstructive pulmonary disease, LVF: Left ventricular failure, ALD: Alcoholic Liver Disease, CKD: Chronic Kidney Disease, Others-snake bite, hypoxia, bee sting, Diabetic ketoacidosis, Anaemia, pyrexia of unknown origin.

\section{Figure 1: Pattern of distribution of diagnosis among patients.}

Most common indication for admission was found to be Poisoning $(32 \%)$ of which $19.3 \%$ of organophosphate poisoning followed by Multi Organ Dysfunction Syndrome (MODS) or multi organ failure (13.3\%), cerebrovascular accidents (12\%), and lower respiratory tract infections $(7.33 \%)$.

Cardio Vascular accident (CVA) being the most common diagnosis in elderly age group compared to MODS in adults. Other indications were shown in Figure1. Common route of drug administration was found to be intravenous (100\%) and other routes were shown in Figure 2. 


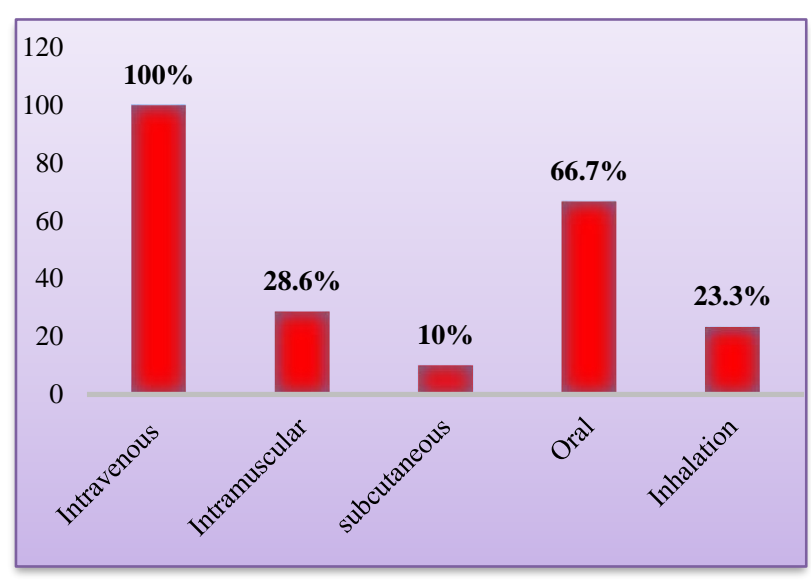

Figure 2: Common routes of administration.

\section{Drug utilization pattern}

A total of 150 patients received 1014 drugs. Drugs acting on gastro intestinal tract $(197 ; 19.4 \%)$ were the most commonly prescribed group of drugs found in 135 prescriptions. They included pantoprazole-proton pump inhibitor $(11.6 \%)$, ondansetron-5 $\mathrm{HT}_{3}$ antagonist (4.5\%) and ranitidine $-\mathrm{H}_{2}$ blocker (3.25\%). Antimicrobials (195; $19.2 \%$ ) were the second most common group of drugs prescribed in 115 prescriptions. Among antimicrobials third generation cephalosporins (cefotaxime and ceftriaxone) were most commonly used in $61 \%$ of prescriptions followed by metronidazole in $24 \%$ of prescriptions. Other group of drugs detailed in table1. Piperacilin+tazobactum was the most common fixed dose combination found in our study. Other FDCs were amoxicillin+clavulunic acid, ATT (Isoniazid, rifampicin, pyrazinamide and ethambutol), cefoperazone+sulbactum.
Furosemide-a loop diuretic was the often given antihypertensive $(21 \%)$ followed by mannitol $(17.3 \%)$ and calcium channel blockers $(10 \%)$.

Table 1: Commonly prescribed drug groups /classes.

\begin{tabular}{|lll|}
\hline Drug class & $\begin{array}{l}\text { No. of drugs } \\
(\mathbf{n = 1 0 1 4})\end{array}$ & $\%$ \\
\hline $\begin{array}{l}\text { Drugs acting on GIT } \\
\text { (Pantoprazole+Ondansetron } \\
\text { +Ranitidine) }\end{array}$ & 197 & 19.4 \\
\hline Antimicrobials & 195 & 19.2 \\
\hline Antihypertensives & 99 & 9.76 \\
\hline Intravenous fluids & 87 & 8.57 \\
\hline Antiplatelets & 72 & 7.10 \\
\hline Drugs for poisoning & 58 & 5.71 \\
\hline Multivitamins & 55 & 5.42 \\
\hline Inhaled bronchodilators & 37 & 3.64 \\
\hline Hypolipidemics & 26 & 2.56 \\
\hline Analgesics & 26 & 2.56 \\
\hline
\end{tabular}

\section{Analysis of prescription indicators}

Analysis of prescriptions using WHO core indicators revealed that the average number of drugs prescribed per prescription was $6.76(\mathrm{n}=1014)$. The minimum and maximum number of drugs prescribed to a single patient was 2 and 12, respectively. Percentage of number of drugs per prescription shown in Figure 3.

There were $115(76.7 \%)$ encounters with antibiotics. All the prescriptions had at least an injectable (100\%). Of all the drugs prescribed $657(64.79 \%)$ drugs abided to the WHO essential drug list, $416(41.02 \%)$ drugs were prescribed by generic name (Table 2 ).

Table 2: Comparison of WHO prescription indicators in various studies.

\begin{tabular}{|llllll|}
\hline WHO Prescribing Indicators & Number & Current study & Kaur et al. & $\begin{array}{l}\text { Sulaiman Sait } \\
\text { et al. }\end{array}$ & $\begin{array}{l}\text { WHO ideal values } \\
\text { (averages/percentage) }\end{array}$ \\
\hline $\begin{array}{l}\text { Average number of drugs per } \\
\text { prescription }\end{array}$ & 1014 & 6.76 & 4.9 & 2.6 & $1.6-2.0$ \\
\hline $\begin{array}{l}\text { Percentage of prescription } \\
\text { with antibiotics }\end{array}$ & 115 & 76.0 & 14.89 & 15.0 & $20-26.8$ \\
\hline $\begin{array}{l}\text { Percentage of prescription } \\
\text { with injection }\end{array}$ & 150 & 100 & 75.17 & 67.5 & $13.4-24.1$ \\
\hline $\begin{array}{l}\text { Percentage of drugs prescribed } \\
\text { by generic name }\end{array}$ & 416 & 41.0 & 29.27 & 37.6 & 100 \\
\hline $\begin{array}{l}\text { Percentage of drugs from } \\
\text { essential drug list }\end{array}$ & 657 & 64.8 & 64.94 & 16.9 & 100 \\
\hline
\end{tabular}

\section{DISCUSSION}

The emergency department of a tertiary care hospital in a developing country is often faced with the problem of heavy patient load and relative paucity of human and economic resources. Specifically, our hospital is a premier tertiary care hospital which caters to a large population pool of this region. In the present study, the drug use pattern in emergency medicine department for 
different clinical emergencies was studied for the first 48 hours. We evaluated 150 cases admitted in Emergency medicine ward of a tertiary care hospital. Male preponderance $(65.33 \%)$ was observed and male: female was in accordance with the previous studies. ${ }^{2,9}$ The most common diagnosis was found to be poisoning followed by Septic shock and MODS and CVA.

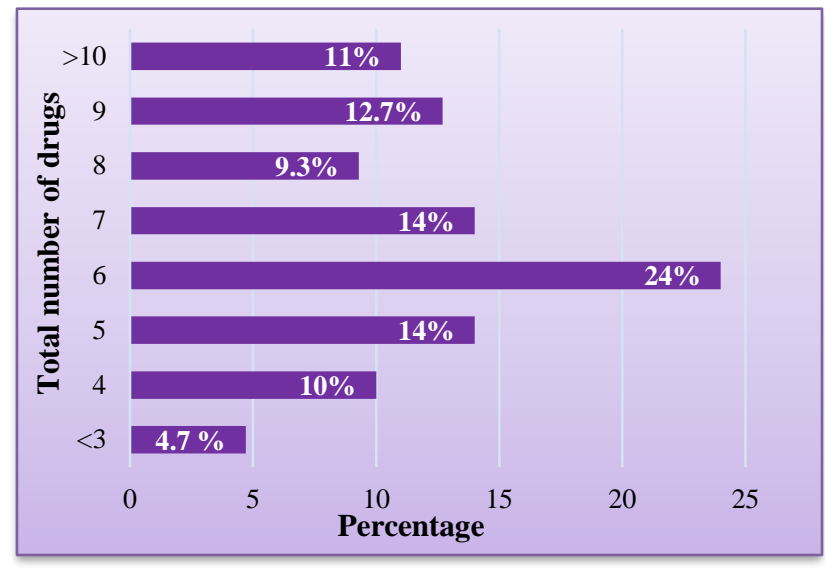

Figure 3: Percentage of drugs per prescription.

All the Acute Coronary Syndrome cases were managed by Sri Jayadeva Institute of cardiovascular sciences which is located inside our KR. Hospital campus. This picture is representative of our medical emergency set-up which caters to wide range of diseases presenting in acute forms.The drugs acting on gastrointestinal tract, e.g. pantoprazole, ondansetron and ranitidine were most commonly prescribed empirical therapy in our study which was seen in 135 prescriptions and was similar to study by Ramesh et al. ${ }^{10}$

Physicians recommended pantoprazole as GI prophylaxis in patients not taking oral feeds or those receiving nonsteroidal anti-inflammatory drugs, aspirin and corticosteroid who were at a higher risk of developing gastric mucosal damage. PPIs are safe and efficacious for elevating intragastric $\mathrm{pH}$ in critically ill-patients for prevention of bleeding from stress-related mucosal damage. ${ }^{11}$ However, a study mentioned H2-receptor antagonists as appropriate initial agents, although PPIs have become first-line therapy in an increasing percentage of critical care patients, despite limited data regarding their use in this population. ${ }^{12}$ Patanwala et al. suggested that ondansetron may be used as a first-line agent for relief of nausea or vomiting for most patients in the emergency department. ${ }^{13}$

Average number of drugs per prescription was 6.76 which is more than double the average number (Ideal 1.61.8) recommended by WHO ${ }^{6}$ However, this cannot be considered as irrational polypharmacy practice as there is need of empirical therapy till definitive diagnosis is made and there is a need for more number of drugs for the management of acute life threatening conditions.
However, it is always preferable to keep the mean number of drugs per prescription as low as possible to minimize the adverse effects, drug interactions and to reduce the cost of therapy. According to various studies conducted in India, there is higher incidence of polypharmcy in emergency set-ups. The incidence of polypharmacy was found to be 4.9 by Kaur et al, 4.2 by Cheekavolu et al whereas Barot et al has reported the use of drugs to be as high as $9.9 \pm 2.5$ drugs per prescription. ${ }^{2,3,9}$

More than fifty percent of drugs were prescribed by brand name. Physician prefers to write brand names which may be an evidence of vigorous promotional strategies by pharmaceutical companies. Physicians also opine that prescribing by generic name may result in the purchase of drugs of uncertain bioavailability due to lack of awareness about bioequivalence. Prescribing by generic name will help the hospital pharmacy to purchase the drugs on contract basis, as the number of brands will be less. It can also reduce the confusion among the pharmacists while dispensing, eliminates the chance of duplication of drug products and reduces the cost of therapy.

Similarly, number of encounters with injectables was on the higher end $(100 \%)$, which again seems justifiable on account of need of immediate drug action in emergency and as the patients will be intolerant to oral medications. Intravenous pantoprazole added to the higher propensity of injectables as it was seen in $>75 \%$ prescriptions. Drugs prescribed from the WHO essential medicine list comprised about $64.79 \%$ of drugs which was higher on comparison with other studies. ${ }^{8}$ This proportion should have been higher since this list of drugs is prepared with regard to public health relevance, evidence on efficacy and safety of the drugs, and comparative cost effectiveness.

Present study depicts the higher antibiotic utilization $(76.66 \%)$ similar to previous literature. ${ }^{9,10}$ Third generation cephalosporins were most commonly prescribed which was found similar to study by Ramesh et al. ${ }^{10}$ It is difficult to suggest the empirical antimicrobials for admitted patients due to underutilization of antibiotic culture- sensitivity testing, which requires about $48-72 \mathrm{hrs}$ to obtain culture sensitivity report, and overestimation of the illness. But what is essential is to narrow down the therapy which was done after obtaining sensitivity report for the infecting organism. Apart from the benefit of reduced cost, this will also help combat drug resistance due to inadvertent use of antibiotics. The antimicrobial combination covering gram positive, gram negative, aerobic and anaerobic organisms should be considered for the septicemia due to high mortality. The selection of initial appropriate antibiotic regimen is important for reducing the mortality and to improve patient outcomes. 
The Procalcitonin (PCT) has been identified as a surrogate marker for estimating the likelihood of a bacterial infection (PCT levels $>0.5 \mu \mathrm{g} / \mathrm{l}$ : very likely chances of bacterial infection and levels $<0.1 \mu \mathrm{g} / \mathrm{l}$ : very unlikely chances of bacterial infection). ${ }^{14}$ The use of PCT guided antibiotic management has been shown to markedly reduce the overuse of antibiotic therapy without an apparent negative impact on patient outcome in 11 randomized controlled trials including 3500 patients from different European countries. ${ }^{15}$ Due to the unavailability of PCT assays in our hospital and financial constraint of patients attending government set up, PCT guided management was not done. Other biomarkers may have better potential in the prognostic assessment of sepsis on admission are adrenomedullin, atrial, natriuretic peptide (ANP) copeptin-stoichiometrically converted to vasopressin. ${ }^{14}$

\section{Limitations}

Single centric and small sample size were the limitations of present study. The study used WHO prescribing indicators which measures the aspects of outpatient treatment. Prescriptions were analysed only for $48 \mathrm{hrs}$.

\section{CONCLUSION}

Drug utilization research is a component of medical audit that plays an important role in pharmaco-epidemiological studies. This study highlights the need for rationalising drug therapy in the emergency settings with regard to increasing adherence to national drug policies and increasing prescription of drugs by generic name. Most of the drugs were from essential drug list.

Also, there is need to prevent inappropriate overuse of PPI and antimicrobials where it is not indicated so that polypharmacy can be reduced. All required investigations and essential drugs should be made available $24 \times 7$ for the better drug utilization in government set up. Further studies are required to confirm the results in a larger population and for optimizing patient drug therapy by formulating hospital drug policy for emergency patient care.

\section{ACKNOWLEDGEMENTS}

Authors would like to thank Dr. Ravishankar AG, Professor and HOD, Department of General Medicine, Mysore Medical College and Research Institute for his guidance and support in carrying out this study. Authors would also extend their thanks to the entire staff of MMC and RI and K.R. Hospital, Mysuru for their cooperation throughout the conduct of this study. Special thanks to statistician, Dr. Lancy D Souza for helping us with the statistical analysis. Authors would also like to convey thanks to case records of patients used in our study.

Funding: No funding sources

Conflict of interest: None declared
Ethical approval: The study was approved by the Institutional Ethics Committee

\section{REFERENCES}

1. Sachdeva PD, Patel BG. Drug utilization studies Scope and future perspectives. Int J Pharm Biol Res. 2010;1(1):11-7.

2. Kaur S, Rajagopalan S, Kaur N, Shafiq N, Bhalla A, Pandhi P. Drug utilization study in medical emergency unit of a tertiary care hospital in North India. Emergency Medicine International. 2014;973578:1-5.

3. Cheekavolu C, Pathapati RM, Babasaheb Laxmansingh K, Saginela SK, Makineedi VP, Siddalingappa et al. Evaluation of drug utilization patterns during initial treatment in the emergency room: a retroprospective pharmacoepidemiological study. ISRN Pharmacol. 2011;261585.

4. Al Balushi, KA, Al-Shibli,S, Al-Zakwani, I. Drug utilization patterns in the emergency department: A retrospective study. J Basic Clin Pharm. 2013;5(1):16.

5. Geneva: WHO. World Health Organization. How to Investigate Drug Use in Health Facilities: selected Drug Use Indicators; 1993:1-87. WHO/DAP/93.1.

6. Isah AO, Ross-Degnan D, Quick J, Laing R, Mabadeje AFB. The development of standard values for the WHO drug use prescribing indicators.ICUM/EDM/ WHO. Available from: http://archives.who.int/prduc2004/rducd/ICIUM_Pos ters/1a2_txt.htm.

7. WHO. Essential Drugs List 19th list. Available from: http://www.who.int/medicines/publications/essential medicines/EML2015_8-May-15.pdf

8. Sait MS, Sarumathy S, Anbu J, Ravichandiran V. Study of drug utilization pattern in a tertiary care hospital during the inpatient admittance in the emergency care department. Asian J Pharm Clin res. 2014;7(1):146-8.

9. Barot PA, Malhotra SD, Rana DA, Patel VJ, Patel KP. Drug utilization in emergency medicine department at a tertiary care teaching hospital: a prospective study. J Basic Clin Pharm. 2013;4(4):7881.

10. Ramesh L. Study of drug prescriptions in medical in-patients in a teaching hospital. Int J Basic Clin Pharmacol. 2016;5(6):2630-33.

11. Jung R, MacLaren R. Proton-pump inhibitors for stress ulcer prophylaxis in critically ill patients. Ann Pharmacother. 2002;36:1929-37.

12. Daley RJ, Rebuck JA, Welage LS, Rogers FB. Prevention of stress ulceration: current trends in critical care. Crit Care Med. 2004;32:2008-13.

13. Patanwala AE, Amini R, Hays DP, Rosen P. Antiemetic therapy for nausea and vomiting in the emergency department. J Emerg Med. 2010;39:3306.

14. Schuetz P, Christ-Crain M, Wolbers M, Schild U, Thomann R, Falconnier C et al. Procalcitonin guided 
antibiotic therapy and hospitalization in patients with lower respiratory tract infections: A prospective, multicenter, randomized controlled trial. BMC Health Serv Res. 2007; 7:102.

15. Reinhart K, Hartog CS. Biomarkers as a guide for antimicrobial therapy. Int $\mathrm{J}$ Antimicrob Agents. 2010;36:S17-21.
Cite this article as: Mamatha V, Parashivamurthy BM, Suneetha DK. Study of drug utilization pattern in emergency medicine ward at a tertiary care teaching hospital. Int J Basic Clin Pharmacol 2017;6:868-73. 